\title{
Does carotid-ankle vascular index reflect proper vascular distensibility in hemodialysis patients?
}

\author{
Tomoji Matsumae and Kazuo Ueda \\ Hypertension Research (2009) 32, 641-642; doi:10.1038/hr.2009.97; published online 3 July 2009
}

\begin{abstract}
$\mathrm{C}$ ardiovascular disease (CVD) accounts for more than $50 \%$ of deaths among patients with end-stage renal disease (ESRD). ${ }^{1,2}$ Arterial stiffness is increased in ESRD patients, in part because of the advanced atherosclerosis that occurs during aging. ${ }^{3}$ Arterial stiffness assessed by pulse wave velocity (PWV) has been established for nearly 10 years as an independent prognostic factor for CVD and as all-cause mortality in patients with ESRD, ${ }^{4,5}$ essential hypertension or type 2 diabetes, and in elderly individuals. ${ }^{6-8}$

Compared with aortic PWV, which is evaluated by carotid-femoral PWV or heartfemoral PWV, brachial-ankle PWV (baPWV) can be more easily measured as an indicator of arterial stiffness without special technical procedures. Moreover, Yamashina et al. ${ }^{9}$ demonstrated that baPWV has considerably high validity and reproducibility and correlates well with aortic PWV, which can be obtained using a catheter-tip manometer. Therefore, baPWV has been widely utilized to screen vascular damage, even though it is not without its own drawbacks. The baPWV measurement ranges from an optimal point of the descending aorta to the ankle, meaning that the PWV of the arterial muscular layer is the main component of measurement. However, it may be difficult to avoid the effects of the upper limb muscular artery on the measured values. In contrast, baPWV can also be influenced by several other factors, including blood pressure (BP) and autonomic nerve function. ${ }^{10,11}$ Thus,
\end{abstract}

Dr T Matsumae and $\mathrm{K}$ Ueda are at the Department of Internal Medicine, Kyorinkai Murakami Memorial Hospital, 1799, Moro-Machi, Nakatsu, Oita 871-0049, Japan.

E-mail: kyorin-m@arion.ocn.ne.jp
baPWV measurement values may vary in the same person according to oscillations in BP.

Recently, the carotid-ankle vascular index (CAVI) has been developed in Japan as a new arterial distensibility index. This index, which is adjusted for BP on the basis of the stiffness parameter $\beta$, can be obtained using VaSera (Fukuda Denshi Co. Ltd, Tokyo, Japan), and it has been reported to have high measurement reproducibility. ${ }^{12-14}$ CAVI has been proposed to be independent of $\mathrm{BP}$ and to offer a proper measurement of vascular stiffness. Several papers have reported that there is no significant association between CAVI and BP, or at most, a very weak relation if one exists. ${ }^{14-16}$ This fact has also been confirmed in patients with ESRD who were treated with hemodialysis (HD). ${ }^{12,13}$ In an article appearing in this issue, Ueyama et al. ${ }^{17}$ provide a detailed description of CAVI measurements in HD patients, and they demonstrate that CAVI is increased in HD patients compared with age- and gender-matched controls. In contrast to earlier reports, they show that the correlations between CAVI and other clinical variables, such as age, systolic BP and the maximum intima-media thickness of the carotid artery, are similar to those between baPWV and the same parameters. It is noteworthy that they demonstrate an effect of water volume changes on both CAVI and baPWV by taking the two measurements simultaneously, both immediately before and after HD. The influence of $\mathrm{HD}$ on vascular compliance is still controversial. Kosch et al. ${ }^{18}$ measured aortic PWV before and after HD or on the next dialysis-free day in HD patients. They found that aortic PWV remained constant over three measurements. In contrast, $\mathrm{Su}$ et al. ${ }^{19}$ demonstrated that baPWV increased after HD in 89 patients, despite a significant decrease in body weight and BP. Meanwhile, Ueyama et al. ${ }^{17}$ observed that, although values for systolic and diastolic $\mathrm{BP}$, as well as baPWV, decreased after HD, CAVI increased after HD. Moreover, in patients with a large water removal rate (that is, large weight gain inter-HD), increases in CAVI during HD were more prominent. They suggested that an increase in vascular tone results from augmented sympathetic nerve activity and that the growing hemoconcentration of blood during HD promotes the increase in CAVI after HD. From this point of view, patients with large weight gains inter-HD may incur large alterations of vascular tone during every HD therapy. Therefore, it will be very interesting to see whether a large change in CAVI during HD can predict a patient's long-term survival.

One limitation of CAVI is that this index is not available for patients with peripheral arterial diseases (PAD), and the prevalence of $\mathrm{PAD}$ in $\mathrm{HD}$ patients is considerably high. ${ }^{20,21}$ Indeed, our earlier study ${ }^{20}$ showed that the frequency of PAD, defined as $<0.9$ by the ankle-brachial pressure index (ABPI), was $43.6 \%$ in diabetic HD patients and $28.4 \%$ in non-diabetic HD patients. At present, the number of diabetic patients who need HD is growing, and patients with HD are likely to also have severe systemic atherosclerosis. As a result, the number of patients on HD, whose arterial stiffness is equivocal when CAVI cannot be correctly used for the evaluation of their peripheral artery status, will increase; however, this information is essential for determining the prognosis or outcome of HD patients, as aforementioned. Therefore, we are hopeful for a newly developed method that can determine exact arterial stiffness by modifying CAVI with ABPI and thereby 
enable an easy examination and definitive detection of arterial distension in various patients with severe $\mathrm{PAD}$, including patients undergoing HD.

1 Lindner A, Charra B, Sherrard DJ, Scribner BH. Accelerated atherosclerosis in prolonged maintenance hemodialysis. N Engl J Med 1974; 290: 697-701.

2 Nakai S, Wada A, Kitaoka T, Shinzato T, Nagura Y, Kikuchi K, Masakane I, Shinoda T, Yamazaki C, Sakai R, Marubayashi S, Morita O, Iseki K, Usami T, Kimata N, Suzuki K, Tabei K, Fushimi K, Miwa N, Yauchi M, Wakai K, Akiba T. An over view of regular dialysis treatment in Japan (as of 31 December 2004). Ther Apher Dial 2006; 10: 476-497.

3 London GM, Guerin AP, Marchais SJ, Pannier B, Safar ME, Day M, Metivier F. Cardiac and arterial interactions in end-stage renal disease. Kidney Int 1996; 50: 600-608.

4 Shoji T, Emoto M, Shinohara K, Kakiya R, Tsujimoto Y, Kishimoto H, Ishimura E, Tabata T, Nishizawa Y. Diabetes mellitus, aortic stiffness, and cardiovascular mortality in end-stage renal disease. J Am Soc Nephrol 2001; 12: 2117-2124.

5 Guerin AP, Blacher J, Pannier B, Marchais SJ, Safar ME, London GM. Impact of aortic stiffness attenuation on survival of patients in end-stage renal failure. Circulation 2001; 103: 987-992.

6 Laurent S, Boutouyrie P, Asmar R, Gautier I, Laloux B, Guize L, Ducimetiere P, Benetos A. Aortic stiffness is an independent predictor of all-cause and cardiovascular mortality in hypertensive patients. Hypertension 2001; 37: 1236-1241.
7 Meaume S, Rudnichi A, Lynch A, Bussy C, Sebban C, Benetos A, Safar ME. Aortic pulse wave velocity as a marker of cardiovascular disease in subjects over 70 years old. J Hypertens 2001; 19: 871-877.

8 Boutouyrie P, Tropeano AI, Asmar R, Gautier I, Benetos A, Lacolley P, Laurent S. Aortic stiffness is an independent predictor of primary coronary events in hypertensive patients: a longitudinal study. Hypertension 2002; 39: 10-15.

9 Yamashina A, Tomiyama H, Takeda K, Tsuda H, Arai T, Hirose K, Koji Y, Hori S, Yamamoto Y. Validity, reproducibility, and clinical significance of noninvasive brachial-ankle pulse wave velocity measurement. Hypertension Res 2002; 25: 359-364.

10 Nakao M, Nomura K, Karita K, Nishikitani M, Yano E. Relationship of bradykinin B2 receptor gene polymorphism with essential hypertension and left ventricular hypertrophy. Hypertension Res 2004; 27: 925-931.

11 Tomiyama H, Yamashina A, Arai T, Hirose K, Koji Y, Chikamori T, Hori S, Yamamoto Y, Doba N, Hinohara S. Influences of age and gender on results of noninvasive brachial-ankle pulse wave velocity measurement-a survey of 12517 subjects. Atherosclerosis 2003; 166: 303-309.

12 Shirai K, Utino J, Otsuka K, Takata M. A novel blood pressure-independent arterial wall stiffness parameter; cardio-ankle vascular index (CAVI). J Atheroscler Thromb 2006; 13: 101-107.

13 Kubozono T, Miyata M, Ueyama K, Nagaki A, Otsuji Y, Kusano K, Kubozono O, Tei C. Clinical significance and reproducibility of new arterial distensibility index. Circ J 2007: 71: 89-94.

14 Takaki A, Ogawa H, Wakeyama T, Iwami T, Kimura M, Hadano Y, Matsuda S, Miyazaki Y, Hiratsuka A, Matsuzaki M. Carotid-ankle vascular index is superior to brachial-ankle pulse wave velocity as an index of arterial stiffness. Hypertens Res 2008; 31: 1347-1355.

15 Ibata J, Sasaki H, Kakimoto T, Matsuno S, Nakatani M, Kobayashi M, Tatsumi K, Nakano Y, Wakasaki H, Furuta $\mathrm{H}$, Nishi M, Nanjo K. Cardio-ankle vascular index measures arterial wall stiffness independent of blood pressure. Diabetes Res Clin Pract 2008; 80: 265-270.

16 Takenaka T, Hoshi H, Kato N, Kobayashi K, Takane H, Shoda J, Suzuki H. Carotid-ankle vascular index to screen cardiovascular diseases in patients with endstage renal diseases. J Atheroscler Thromb 2008; 15: 339-344.

17 Ueyama K, Miyata M, Kubozono T, Nagaki A, Hamasaki S, Ueyama S, Tei C. Noninvasive indices of arterial stiffness in hemodialysis patients. Hypertens Res 2009; 32: 716-720.

18 Kosch M, Levers A, Barenbrock M, Matzkies F, Schaefer RM, Kisters K, Rahn KH, Hausberg M. Acute effects of haemodialysis on endothelial function and large artery elasticity. Nephrol Dial Transplant 2001; 16: 1663-1668.

19 Su HM, Chang JM, Lin FH, Chen SC, Voon WC, Cheng $\mathrm{KH}$, Wang CS, Lin TH, Lai WT, Sheu SH. Influence of different measurement time points on brachial-ankle pulse wave velocity and ankle-brachial index in hemodialysis patients. Hypertens Res 2007; 30: 965-970.

20 Matsumae T, Abe Y, Murakami G, Ueda K, Saito T. Effect of glucose metabolism on aortic pulse wave velocity in hemodialysis patients with and without diabetes. Hypertens Res 2008; 31: 1365-1372.

21 Ono K, Tsuchida A, Kawai H, Matsuo H, Wakamatsu R, Maezawa A, Yano S, Kawada T, Nojima Y. Ankle-brachial blood pressure index predicts all-cause and cardiovascular mortality in hemodialysis patients. J Am Soc Nephrol 2003; 14: 1591-1598. 